\title{
Plasma Content of $\mathrm{B}_{6}$ Vitamers and Its Relationship to Hepatic Vitamin $\mathrm{B}_{6}$ Metabolism
}

\author{
Lawrence Lumeng, Alec LuI, and Ting-KaI Li, Veterans Administration Hospital \\ and Departments of Medicine and Biochemistry, Indiana University \\ School of Medicine, Indianapolis, Indiana 46223
}

A B S T RACT The plasma content of $B_{6}$ vitamers is governed by, among other factors, dietary supply and metabolic interconversion. This study examines the effect of pyridoxine supplementation on the plasma content of $B_{6}$ vitamers and pyridoxic acid in man, and the metabolic conversion and release of $B_{6}$ compounds in isolated rat hepatocytes. Six healthy human subjects were given $100 \mathrm{mg}$ pyridoxine- $\mathrm{HCl} / \mathrm{d}$ orally for $1-3 \mathrm{wk}$. Before pyridoxine supplementation, the mean total plasma level of $\mathrm{B}_{6}$ vitamers was $114 \pm 9 \mathrm{nM}$; and pyridoxal-P, pyridoxamine-P, pyridoxal, pyridoxine, and pyridoxamine accounted for $54,3,11,27$, and $5 \%$, respectively. Plasma level of pyridoxic acid was $40 \pm 7$ $\mathrm{nM}$. Thus, pyridoxal- $\mathrm{P}$ is the principal $\mathrm{B}_{6}$ vitamer in plasma. During pyridoxine supplementation, mean plasma levels of the $B_{6}$ vitamers and pyridoxic acid increased to $655 \pm 122$ and $222 \pm 55 \mathrm{nM}$, respectively. The plasma content of pyridoxal-P and pyridoxic acid increased 6-7-fold and that of pyridoxal, 12-fold, but the pyridoxine level did not increase. Isolated hepatocytes, $1 \mathrm{~g} / 15 \mathrm{ml}$, were incubated for $2 \mathrm{~h}$ with $3.33 \mu \mathrm{M}$ $\left[{ }^{14} \mathrm{C}\right]$ pyridoxine $(6 \mu \mathrm{Ci} / \mu \mathrm{mol})$. At zero time, the cells contained about $35 \mathrm{nmol}$ pyridoxal-P and $25 \mathrm{nmol}$ pyridoxamine-P. After $2 \mathrm{~h}$ incubation, the cellular content of pyridoxal-P and pyridoxamine-P did not change significantly, but the medium contained 5.9 nmol pyridoxal-P, $0.3 \mathrm{nmol}$ pyridoxamine-P, $7.2 \mathrm{nmol}$ pyridoxal, $26.6 \mathrm{nmol}$ pyridoxine, $0.3 \mathrm{nmol}$ pyridoxamine, and $7.5 \mathrm{nmol}$ pyridoxic acid. Whereas the specific radioactivity of pyridoxal-P, pyridoxal, and pyridoxic acid in the medium approached that of $\left[{ }^{14} \mathrm{C}\right]$ pyridoxine, the specific radioactivity of cellular pyridoxal-P and pyridoxamine-P was only $20 \%$ of that of pyridoxine. Thus, newly synthesized pyridoxal- $P$ is not freely exchangeable with endogenous pyridoxal-P, but is preferentially released or degraded to pyridoxal and pyridoxic acid. The latter $B_{6}$ compounds are also released. These results suggest that orally ingested pyridoxine is rapidly

Received for publication 14 March 1980 and in revised form 13 June 1980. metabolized in liver and its products are released into the circulation in the form of pyridoxal-P, pyridoxal, and pyridoxic acid.

\section{INTRODUCTION}

Vitamin $B_{6}$ is metabolized in vivo to multiple vitameric forms and is ultimately excreted as pyridoxic acid in the urine. Pyridoxal-P and pyridoxamine-P, the coenzyme forms, are the major $B_{6}$ compounds in tissues (1), but pyridoxal-P (2) and pyridoxal (3) appear to be the major forms in blood plasma. The quantitative relationship between these $B_{6}$ vitamers and other $B_{6}$ compounds in plasma has not been defined. Such knowledge is important to the understanding of the process of transport of vitamin $B_{6}$ among the different organs and tissues of the body.

Recently, we have modified an existing method (4) for the separation and analysis of the $B_{6}$ compounds. By using this method, we have measured the plasma content of $B_{6}$ vitamers and pyridoxic acid in man before and during pyridoxine supplementation. Because the liver is the most active organ in the metabolism of pyridoxine (5-8) and the sole source of pyridoxal-P in blood plasma (9), we have also studied the metabolic conversion and release of $B_{6}$ compounds in isolated rat hepatocytes. The data indicate a close relationship between hepatic metabolism and the plasma level of the various $B_{6}$ compounds.

\section{METHODS}

Studies on humans. Six healthy human subjects were studied, 5 males and 1 female, 23-38 yr of age. Venous blood samples were collected when they were on a regular diet before and during oral supplementation of pyridoxine- $\mathrm{HCl}$ $100 \mathrm{mg} / \mathrm{d}$. Blood samples were taken in all subjects after $1 \mathrm{wk}$ of pyridoxine supplementation, and in three subjects, samples were collected at weekly intervals for $3 \mathrm{wk}$. The samples were drawn after an overnight fast and immediately before the next daily dose of pyridoxine was administered. Blood samples were collected with $2 \mathrm{mM}$ EDTA, pH 7.4, as anticoagulant, and plasma was separated by centrifugation within 30 $\mathrm{min}$. 
Studies on isolated rat hepatocytes. Male Sprague-Dawley rats weighing 200-300 g were purchased from Harlan Industries, Inc., Indianapolis, Ind. They were maintained for at least 1 wk on a standard laboratory chow (Wayne LabBlox, Allied Mills, Inc., Chicago, Ill.) before use. This diet contains $8.13 \mathrm{ppm}$ pyridoxine- $\mathrm{HCl}, 1.13 \mathrm{ppm}$ in excess of the amount recommended by the National Research Council, National Academy of Sciences (10). Isolated rat liver cells were prepared as described previously (11). The cell preparations consistently contained $>95 \%$ parenchymal cells. Immediately following isolation, $95 \pm 1 \%( \pm \mathrm{SE}, n=8)$ of the cells excluded trypan blue, and $84 \pm 2 \%$ of the cells continued to exclude the dye following $2 \mathrm{~h}$ of incubation. Cells prepared in this manner exhibited high rates of gluconeogenesis (12), maintained intracellular $\mathrm{K}^{+}$concentrations at $130-150 \mathrm{meq} /$ liter of cell water (13), and were active in protein synthesis (14) and amino acid transport (11).

Freshly isolated hepatocytes, $1 \mathrm{~g}$ wet wt, were incubated at $37^{\circ} \mathrm{C}$ in $15 \mathrm{ml} \mathrm{Krebs-Henseleit} \mathrm{medium} \mathrm{(pH} \mathrm{7.4)} \mathrm{containing}$ $10 \mathrm{mM}$ glucose and $2.5 \mathrm{~g} / 100 \mathrm{ml}$ fatty acid-free bovine serum albumin. Where indicated, $\left[{ }^{14} \mathrm{C}\right]$ pyridoxine $(6 \mu \mathrm{Ci} / \mu \mathrm{mol})$ was also added to the medium to bring its concentration to $3.33 \mu \mathrm{M}$. All incubations were performed in Erlenmeyer flasks in a shaking water bath and in the presence of $95 \% \mathrm{O}_{2}$ and $5 \% \mathrm{CO}_{2}$. At the end of $2 \mathrm{~h}$ incubation, the cell suspensions were centrifuged to separate the cells from the medium as described previously (11).

Analyses. $\mathrm{B}_{6}$ compounds were extracted from samples of plasma and incubation medium by treating $14 \mathrm{ml}$ of the sample with $1.56 \mathrm{ml}$ of $75 \%$ trichloroacetic acid. Trichloroacetic acid was added dropwise at $4^{\circ} \mathrm{C}$ with constant stirring. The treated samples were then heated to $37^{\circ} \mathrm{C}$ for $10 \mathrm{~min}$ and centrifuged for $30 \mathrm{~min}$ at $32,800 \mathrm{~g}$ and $4^{\circ} \mathrm{C}$. The clear supernatant fractions were collected and divided into 2 -ml aliquots. The trichloroacetic acid was extracted by water-saturated and peroxidefree diethyl ether until the $\mathrm{pH}$ was at least 4.5. The samples were frozen at $-20^{\circ} \mathrm{C}$ ovemight and used for assay the next day.

$\mathrm{B}_{6}$ compounds in cell pellets were extracted by adding $6 \mathrm{ml}$ of $7.5 \%$ trichloroacetic acid and homogenizing with a Polytron PT20 homogenizer (Polytron Corp., Elkhart, Ind.) at a power setting of 6 for $1 \mathrm{~min}$. The volume of the suspension of precipitated protein was brought up to $10 \mathrm{ml}$ by adding $7.5 \%$ trichloroacetic acid. The suspension was then heated to $50^{\circ} \mathrm{C}$ for $20 \mathrm{~min}$ and centrifuged. The resultant pellets of precipitated protein were re-extracted by adding $8 \mathrm{ml}$ of $7.5 \%$ trichloroacetic acid and centrifuging. The clear supernatant fractions from the two extraction steps were combined and then divided into $2-\mathrm{ml}$ aliquots for ether extraction. The use of $7.5 \%$ trichloroacetic acid did not chemically alter added $\mathrm{B}_{6}$ vitamers in the extraction procedure. The recovery of pyridoxal- $\mathrm{P}$, the $\mathrm{B}_{6}$ compound most tightly bound to proteins, was $104 \pm 6 \%$ (mean $\pm \mathrm{SD}, n=8$ ).

Fractionation of the $B_{6}$ compounds was performed by a modification of the method originally described by Loo and Cort (4). The strongly acidic cation exchange resin (Bio-Rad AG 50 W-X8, 200-400 mesh; Bio-Rad Laboratories, Richmond, Calif.) was washed three times in $1 \mathrm{~N} \mathrm{HCl}$ to remove fluorescent contaminants. Excess acid was then removed by washing with deionized, distilled water. After washing, the resin was washed again with $1 \mathrm{~N} \mathrm{NaOH}$ and rinsed with water until the $\mathrm{pH}$ was 7.4. The washed resin, free of fluorescent contaminants, was next rinsed with $100 \mathrm{mM}$ formic acid, then $10 \mathrm{mM}$ formic acid, until the $\mathrm{pH}$ was 3.2 or lower. The resin was finally rinsed with $10 \mathrm{mM}$ ammonium formate buffer $(\mathrm{pH}$ 3.2 ) to bring the $\mathrm{pH}$ and conductivity of the effluent to those of the formate buffer. The resin was placed in chromatographic columns $0.7 \times 30 \mathrm{~cm}$ (Bio-Rad Econo-Columns, No. 737-1252; Bio-Rad Laboratories) and packed to a bed height of $10 \mathrm{~cm}$.
The columns were connected by plastic tubings to a Technicon Auto-Analyzer proportioning pump (Technicon Instruments Corp., Tarrytown, N. Y.) to maintain the flow rate at $1 \mathrm{ml} / \mathrm{min}$.

Pyridoxal-P in $10 \mathrm{mM}$ ammonium formate $(\mathrm{pH} \mathrm{3.2)}$ did not adsorb to the cationic resin and it could be eluted with $20 \mathrm{ml}$ of this buffer. By contrast, all the other $B_{6}$ compounds adsorbed to the resin in $10 \mathrm{mM}$ ammonium formate $(\mathrm{pH} 3.2$ ) and could be displaced sequentially by increasing the $\mathrm{pH}$ and ionic strength (Fig. 1): pyridoxic acid with $60 \mathrm{ml}$ of 100 $\mathrm{mM}$ ammonium formate ( $\mathrm{pH} 3.2$ ); pyridoxamine-P with $75 \mathrm{ml}$ of $95 \mathrm{mM}$ sodium acetate $(\mathrm{pH} 4.2)$ and $30 \mathrm{ml}$ of $100 \mathrm{mM}$ sodium acetate $(\mathrm{pH} 5.2$ ); pyridoxal with $60 \mathrm{ml}$ of $120 \mathrm{mM}$ sodium acetate $(\mathrm{pH} 5.6$ ); pyridoxine with $60 \mathrm{ml}$ of $100 \mathrm{mM}$ sodium phosphate ( $\mathrm{pH} 6.5$ ); and pyridoxamine with $60 \mathrm{ml}$ of $120 \mathrm{mM}$ sodium phosphate $(\mathrm{pH} 7.5)$.

All of the $B_{6}$ vitamers were assayed by fluorometric measurements essentially as described by Contractor and Shane (15). Pyridoxic acid was measured by the method of Reddy et al. (16). The recoveries of pyridoxal-P, pyridoxic acid, pyridoxamine-P, pyridoxal, pyridoxine, and pyridoxamine were $98 \pm 3,102 \pm 7,86 \pm 5,109 \pm 7,111 \pm 7$, and $107 \pm 12 \%(n=9)$, respectively. These recovery data were obtained by adding authentic vitamers in amounts equivalent to those present in the samples.

The chromatographic procedure described above did not separate pyridovine-P from pyridoxal-P. By fluorometric assay using the cyanide reaction (15), however, only pyridoxal-P was measured, and pyridoxine-P did not interfere. Indeed, results based on fluorometric assay of tissue and plasma pyridoxal-P after chromatographic separation agreed well with those assayed by tyrosine apodecarboxylase. It is known that pyridoxine-P occurs only in trace amounts in tissues (17).

Deproteinized samples of plasma and medium, $7 \mathrm{ml}$, were diluted with $0.77 \mathrm{ml} 100 \mathrm{mM}$ ammonium formate (pH 3.2) and $17.23 \mathrm{ml} 10 \mathrm{mM}$ ammonium formate (pH 3.2) to bring the final $\mathrm{pH}$ to 3.2 and the conductivity to about $3 \mathrm{mmho}$. $20 \mathrm{ml}$ deproteinized cell extracts were diluted with $2.25 \mathrm{ml}$ $100 \mathrm{mM}$ ammonium formate $(\mathrm{pH} 3.2$ ). These samples were then used for chromatographic separation of the $B_{6}$ compounds.

For each run in which the unknown samples were separated, a sample blank and a standard solution containing $100-$ $1,000 \mathrm{ng}$ of each $\mathrm{B}_{6}$ compound were also analyzed. Alicpuots

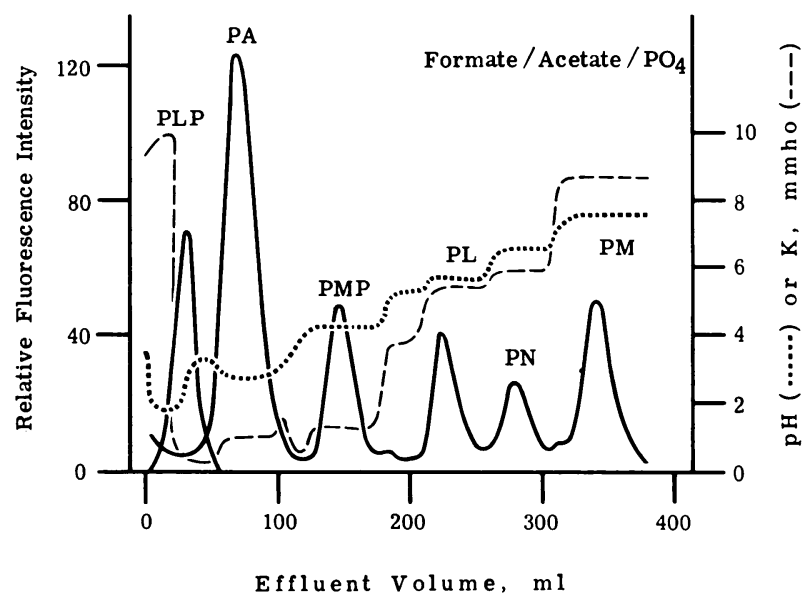

Figure 1 Chromatographic separation of the $B_{6}$ compounds by a strongly acidic cationic exchange resin, AG 50 $\mathrm{W}$-X8. PA, pyridoxic acid; PL, pyridoxal; PLP, pyridoxal-P; PM, pyridoxamine; PMP, pyridoxamine-P; $\mathrm{PN}$, pyridoxine. 


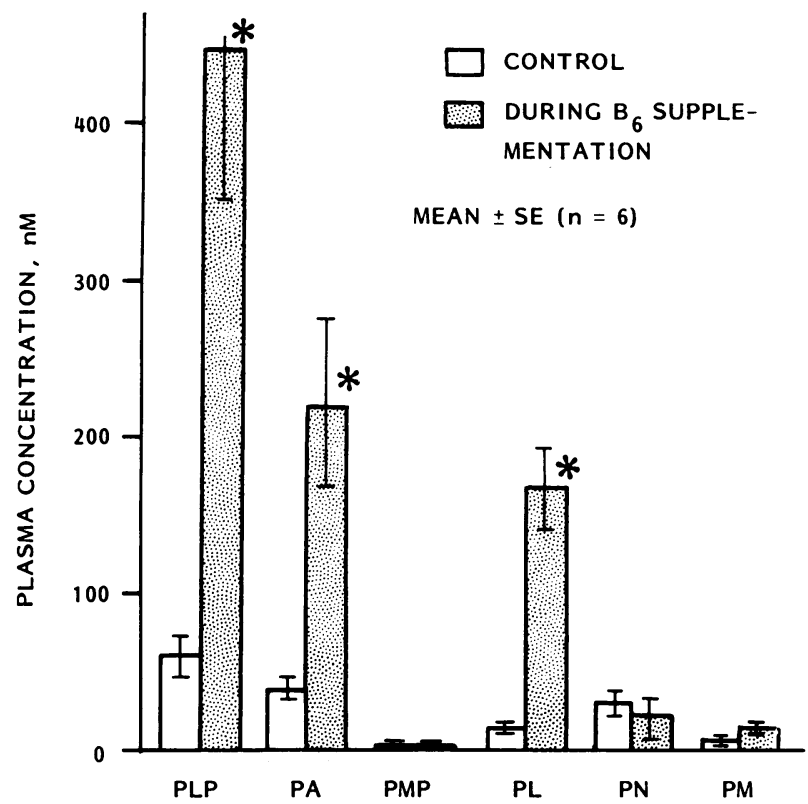

FIgURE 2 Plasma content of $B_{6}$ compounds before and during pyridoxine supplementation $(100 \mathrm{mg}$ pyridoxine- $\mathrm{HCl} / \mathrm{d})$. Abbreviations are the same as in Fig. $1 .{ }^{*}, P<0.01$.

of the effluents from these columns were used for fluorometric and/or isotopic measurements.

All steps and specimens were protected from ordinary room light by the use of darkened rooms and yellow fluorescent lights to avoid photolysis of the $B_{6}$ compounds.
Materials. All of the $\mathrm{B}_{6}$ compounds and other reagents were purchased from Sigma Chemical Co., St. Louis, Mo. $\left[4,5-{ }^{14} \mathrm{C}\right]$ pyridoxine- $\mathrm{HCl}$ was a gift of Dr. Myron Brin (Hoffmann-LaRoche, Inc., Nutley, N. J.). The purity of $\left[{ }^{14} \mathrm{C}\right]$ pyridoxine- $\mathrm{HCl}$ was verified by chromatography.

Statistical analysis. Student's $t$ test was used to determine the significance of the difference between mean values. The results are reported as mean $\pm \mathrm{SE}$.

\section{RESULTS}

In individuals consuming a regular diet, pyridoxal-P and pyridoxic acid were the major $\mathrm{B}_{6}$ compounds found in blood plasma (Fig. 2). Pyridoxal-P constituted $>53 \%$ of the active vitamers. After $1 \mathrm{wk}$ of pyridoxine supplementation, the plasma concentration of pyridoxal-P and pyridoxic acid increased 6-7-fold, whereas that of pyridoxal increased $\sim 12$-fold. In three subjects, the plasma levels of the $B_{6}$ compounds were determined weekly during supplementation for $3 \mathrm{wk}$. They did not fluctuate significantly after the lst wk, indicating that they had attained new steady-state levels within this period. Since pyridoxal-P and pyridoxal are biologically active, and are known to turn over rapidly in vivo (18, 19), the results indicate that these compounds are the major transport forms in the circulation.

To define the relationship of the plasma content of $\mathrm{B}_{6}$ compounds to hepatic vitamin $\mathrm{B}_{6}$ metabolism, studies were performed with intact isolated rat hepatocytes. Hepatocytes were incubated in the presence of $\left[{ }^{14} \mathrm{C}\right]-$

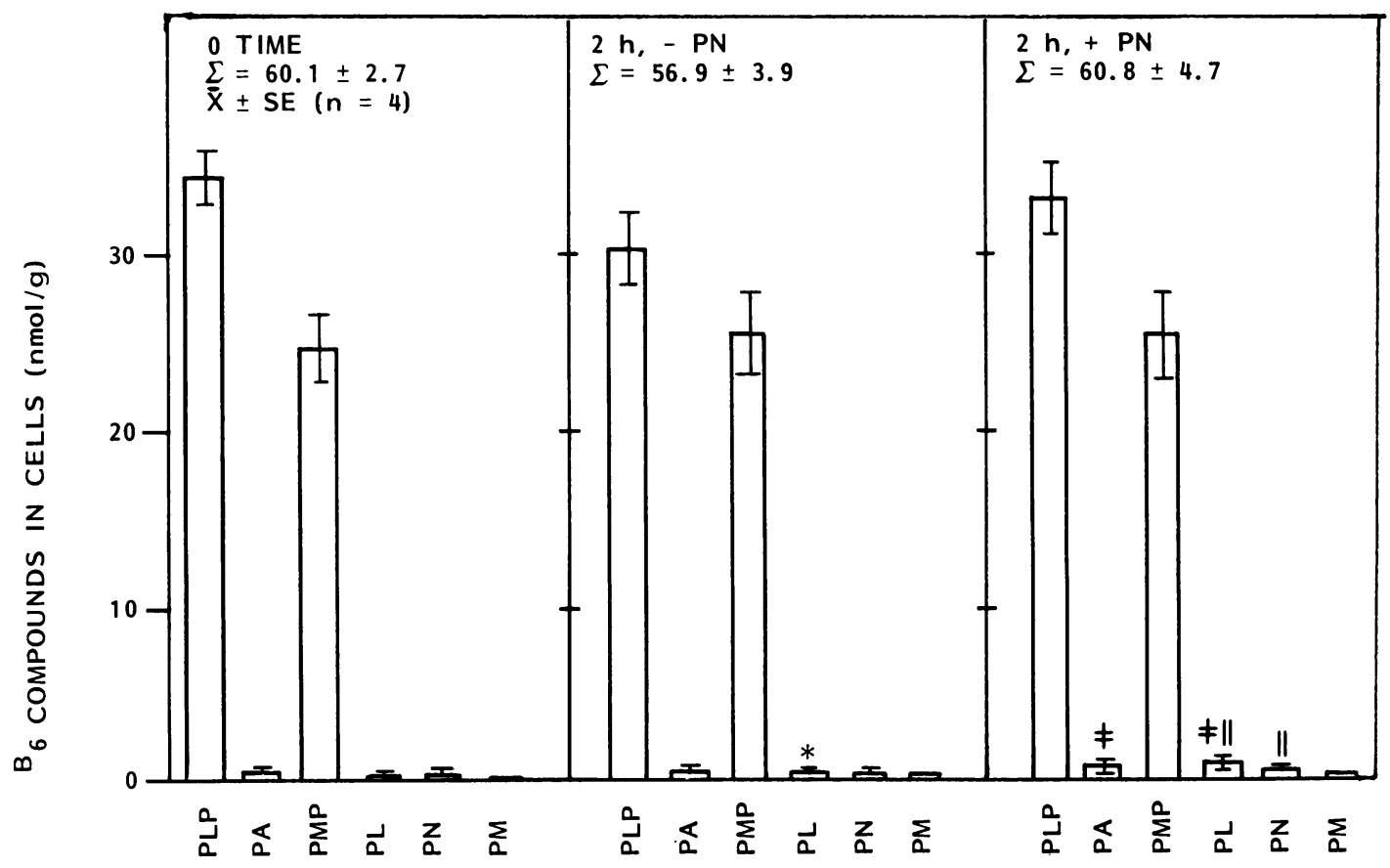

FIGURE 3 Cellular level of $B_{6}$ compounds in isolated hepatocytes before and after incubation with $(+\mathrm{PN})$ and without $(-\mathrm{PN})$ pyridoxine. ${ }^{*}, P<0.05,0$ time vs. $2 \mathrm{~h}-\mathrm{PN} ; \sharp, P<0.05,0$ time vs. $2 \mathrm{~h}+\mathrm{PN}$; ", $P<0.02,2 \mathrm{~h}-\mathrm{PN}$ vs. $2 \mathrm{~h}+\mathrm{PN}$. Abbreviations are the same as in Fig. 1. 


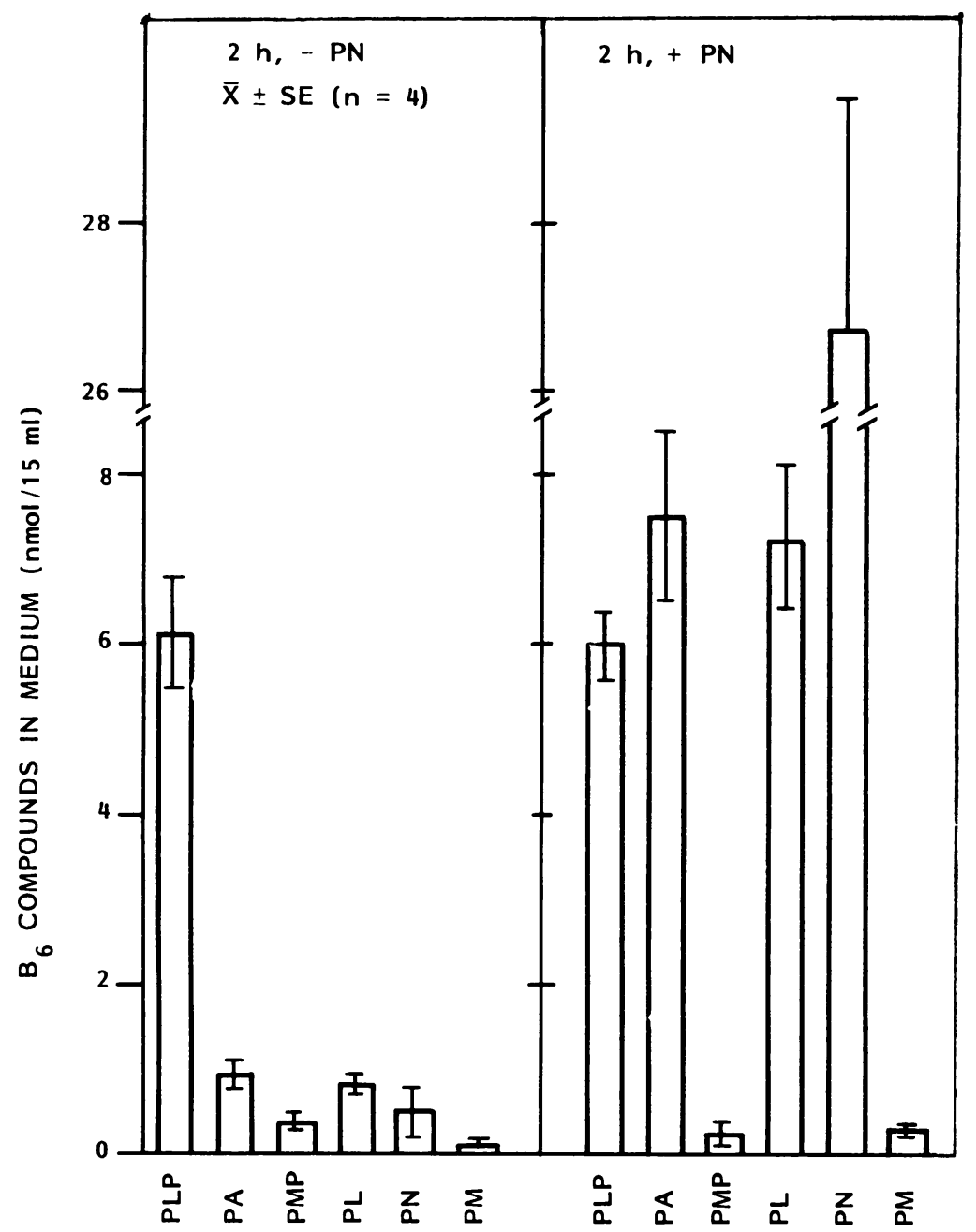

FIGURE 4 Level of $B_{6}$ compounds released into the medium by isolated hepatocytes after incubation in the absence $(-\mathrm{PN})$ and presence of $(+\mathrm{PN})$ of pyridoxine. Abbreviations are the same as in Fig. 1.

pyridoxine, and the hepatic metabolism and release of different $B_{6}$ compounds into the incubation medium were examined by both fluorometric and isotopic measurements.

Fig. 3 shows the cellular level of $B_{6}$ compounds in isolated hepatocytes and the effect of incubation in the absence and presence of $\left[{ }^{14} \mathrm{C}\right]$ pyridoxine. At zero time, the hepatocytes contained $\sim 35 \mathrm{nmol}$ of pyridoxal-P and $25 \mathrm{nmol}$ of pyridoxamine-P per gram wet weight. The contents of these coenzymes are similar to those found in the freeze-clamped liver of $B_{6}$-sufficient rats in situ (20). The content of the other $\mathrm{B}_{6}$ compounds was extremely low. After $2 \mathrm{~h}$ incubation in the absence of radiolabeled pyridoxine, the intracellular levels of the $B_{6}$ compounds did not change except for that of pyridoxal, which increased $(P<0.05)$ from 0.14 to 0.29 $\mathrm{nmol} / \mathrm{g}$. The level of pyridoxal-P tended to decrease, but the change was not statistically significant. Hepato- cytes incubated in the presence of radiolabeled pyridoxine also did not exhibit significant change in the cellular levels of pyridoxal-P and pyridoxamine-P. However, the cellular content of pyridoxic acid increased from 0.36 (at zero time) to $0.73 \mathrm{nmol} / \mathrm{g}$, and that of pyridoxal, from 0.14 to $0.95 \mathrm{nmol} / \mathrm{g}$.

Fig. 4 depicts the levels of the $B_{6}$ compounds released into the medium by isolated hepatocytes after incubation in the absence and presence of $\left[{ }^{14} \mathrm{C}\right]$ pyridoxine. In the absence of added radiolabeled pyridoxine, pyridoxal- $\mathrm{P}$ was the major $\mathrm{B}_{6}$ compound released. However, after $2 \mathrm{~h}$ incubation in the presence of added radiolabeled pyridoxine, large amounts of pyridoxal-P, pyridoxic acid, and pyridoxal were found in the medium. Of the $50 \mathrm{nmol}$ of labeled pyridoxine added to the incubation mixture, $\sim 21 \mathrm{nmol}$ was converted to pyridoxal-P, pyridoxic acid, and pyridoxal in the medium and $\sim 26 \mathrm{nmol}$ remained unmetabolized. Recovery 


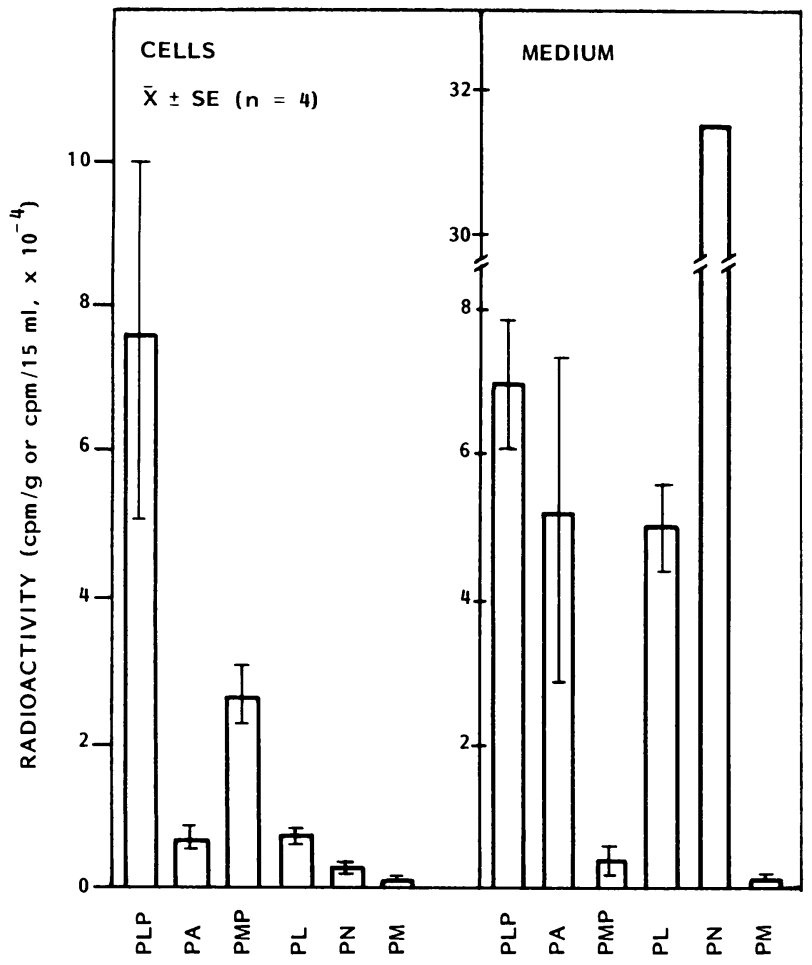

FIguRE 5 Metabolic conversion of $\left[{ }^{14} \mathrm{C}\right]$ pyridoxine by isolated hepatocytes. Abbreviations are the same as in Fig. 1.

was $94 \%$. These findings in vitro with isolated hepatocytes mimic the situation seen in the human subjects during pyridoxine supplementation, i.e., pyridoxal-P, pyridoxic acid, and pyridoxal exhibit the largest increments in plasma (Fig. 2).

Fig. 5 summarizes the metabolic conversion of $\left[{ }^{14} \mathrm{C}\right]-$ pyridoxine by isolated liver cells based on isotopic measurement. The recovery of radioactivity counts in these experiments was $102 \%$ of that of $\left[{ }^{14} \mathrm{C}\right]$ pyridoxine added. About $20 \%$ of the recovered counts were intracellular, and the remainder was in the medium $(51 \%$ as unmetabolized $\left[{ }^{14} \mathrm{C}\right]$ pyridoxine and $29 \%$ as radiolabeled $\mathrm{B}_{6}$ compounds other than $\left[{ }^{14} \mathrm{C}\right]$ pyridoxine). Labeled pyridoxal-P and pyridoxamine-P accounted for $85 \%$ of the total counts in the cell pellet. By contrast, ${ }^{14} \mathrm{C}$-labeled pyridoxal-P, pyridoxic acid, and pyridoxal accounted for $>96 \%$ of the products of $\left[{ }^{14} \mathrm{C}\right]$ pyridoxine that appeared in the medium. The data thus agree well with those shown in Figs. 3 and 4, which assayed the total contents of the $B_{6}$ vitamers by means of fluorometric analysis.

Fig. 6 shows the metabolic conversions of $\left[{ }^{14} \mathrm{C}\right]$ pyridoxine by isolated hepatocytes in the cell pellet and the medium, expressed as specific radioactivities. The specific radioactivity of pyridoxine in the cell and medium was $\sim 12,000 \mathrm{cpm} / \mathrm{nmol}$, similar to that of $\left[{ }^{14} \mathrm{C}\right]-$ pyridoxine added to the incubations. The specific ra- dioactivities of pyridoxal- $\mathrm{P}$ and pyridoxamine- $\mathrm{P}$ in the cell pellet were $<20 \%$ of that of pyridoxine, however. This enormous dilution of radioactive counts indicates that the intracellular endogenous pools of pyridoxal-P and pyridoxamine- $P$ are not readily miscible with the newly synthesized compounds. By contrast, the specific radioactivity of pyridoxal- $P$ in the medium approached that of pyridoxine, suggesting that there is a small but rapidly mobilizable pool of newly synthesized pyridoxal-P in the cell associated with secretion. In the incubation medium, the specific radioactivities of pyridoxic acid and pyridoxal were higher than those of intracellular pyridoxal- $P$ and pyridoxamine-P, suggesting that the newly synthesized pyridoxal-P also tends to be degraded rapidly to pyridoxal and pyridoxic acid and released into the circulation.

Because pyridoxine-P could not be separated from pyridoxal-P by chromatography, and because the fluorometric assay was specific for the latter, its presence can potentially elevate falsely the calculated specific radioactivities of pyridoxal-P shown in Fig. 6. The values for pyridoxal- $P$ in the medium were found to be no higher than that of pyridoxine, however, indicating that little or no radiolabeled pyridoxine-P was in the medium. Within the cell, the specific radioactivity of pyridoxal-P was somewhat higher than that of pyridoxamine-P. Conceivably, there could be a small amount of radiolabeled pyridoxine-P present within the hepatocytes under the conditions of the experiment.

\section{DISCUSSION}

The quantitative determination of the plasma content of vitamin $B_{6}$ has been problematic because of the existence of multiple forms of this vitamin in vivo. Although plasma pyridoxal-P can be assayed enzymatically (2) and both plasma pyridoxal and pyridoxal-P fluorometrically after conversion to their methyl anthranilate derivatives (3), these methods are not directly suitable for the measurement of other $B_{6}$ compounds in plasma. As reported in this communication, we have accomplished successfully the analysis in a single plasma sample of six of the seven $B_{6}$ compounds known to be present in vivo. The method of Loo and Cort (4) was employed to separate the $B_{6}$ compounds, but major modifications were introduced in the elution buffers to improve chromatographic separation. Additionally, the specificity of the fluorometric assays of the $B_{6}$ compounds was enhanced by prior chemical conversion (15).

In human subjects on regular diets, we found that pyridoxal-P accounted for $>50 \%$ of the active $B_{6}$ vitamers in plasma (Fig. 2). Upon supplementation with oral pyridoxine, the levels of both pyridoxal-P and pyridoxal increased 6-12-fold, but pyridoxal-P remained the preponderant $B_{6}$ vitamer. Importantly, 


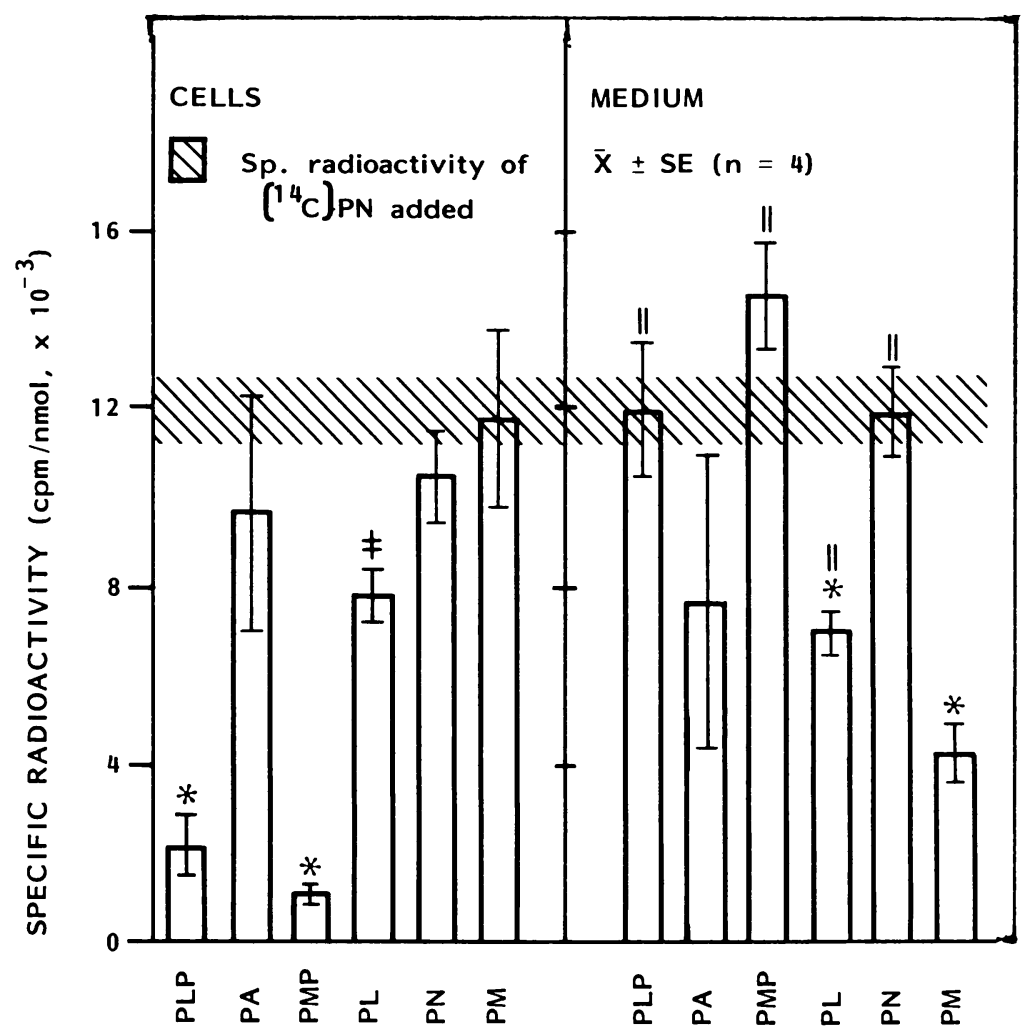

Figure 6 Metabolic conversion of $\left[{ }^{14} \mathrm{C}\right]$ pyridoxine by isolated hepatocytes, expressed as specific (Sp.) radioactivity. ${ }^{*}, P<0.001$ and $\ddagger, P<0.005$, compared with the specific radioactivity of pyridoxine. ", $P<0.005$, compared with the specific radioactivities of cellular PLP and PMP. Abbreviations are the same as in Fig. 1.

plasma pyridoxamine-P occurred only in trace amounts $(<3 \mathrm{nM})$ both before and during pyridoxine supplementation. Therefore, the content of $\mathrm{B}_{6}$ compounds in blood plasma differs significantly from that of whole blood which is known to contain about equimolar amounts $(\sim 60-70 \mathrm{nM})$ of pyridoxal-P and pyridoxamine-P (15). This major difference is consistent with the general observation that pyridoxamine- $\mathrm{P}$ is mainly an intracellular $B_{6}$ vitamer $(1,20)$. Accordingly, the high level of pyridoxamine-P in whole blood must be due to the occurrence of this coenzyme in erythrocytes and other cellular elements. The above findings also confirm the earlier notion (21) that pyridoxal-P is the major $\mathrm{B}_{6}$ vitamer in blood plasma, but implicate both pyridoxal-P and pyridoxal as the transport forms of vitamin $B_{6}$. The propensity of these $B_{6}$ vitamers to circulate in plasma is most likely due to protein binding: pyridoxal-P is known to bind very avidly to albumin, and pyridoxal, less so $(9,22)$. On the other hand, both pyridoxal-P and pyridoxal are also cleared rapidly from plasma in vivo $(18,19)$. Since pyridoxal-P is not excreted at all and pyridoxal only minimally in the urine (15), physiological mechanisms must exist for their transfer into tissues. Because albumin-bound pyri-
doxal-P can be dephosphorylated by phosphatases (9) and pyridoxal can readily permeate biological membranes (20), the findings suggest that pyridoxal is the transport form that ultimately enters various tissues in the body.

Since pyridoxal-P, pyridoxal, and pyridoxic acid exhibited the largest increments in plasma in vivo during supplementation with oral pyridoxine (Fig. 2), it is pertinent to consider the organ sources of these plasma $\mathrm{B}_{6}$ compounds. Previous studies on the effect of organ ablation in dogs (9) have shown that the liver is the sole organ responsible for the formation of plasma pyridoxal-P from either pyridoxine or pyridoxal. On the other hand, pyridoxal in plasma may derive from multiple organ sources. Anderson et al. (18) reported that human erythrocytes can convert pyridoxine into pyridoxal and release the latter compound into the medium. The results reported here with isolated hepatocytes indicate that the liver can also release pyridoxal into the circulation, as well as pyridoxal-P and pyridoxic acid (Figs. 4 and 5). Although the relative and quantitative importance of erythrocytes and liver in converting ingested pyridoxine to plasma pyridoxal is uncertain at this time, it is known that the liver is the most 


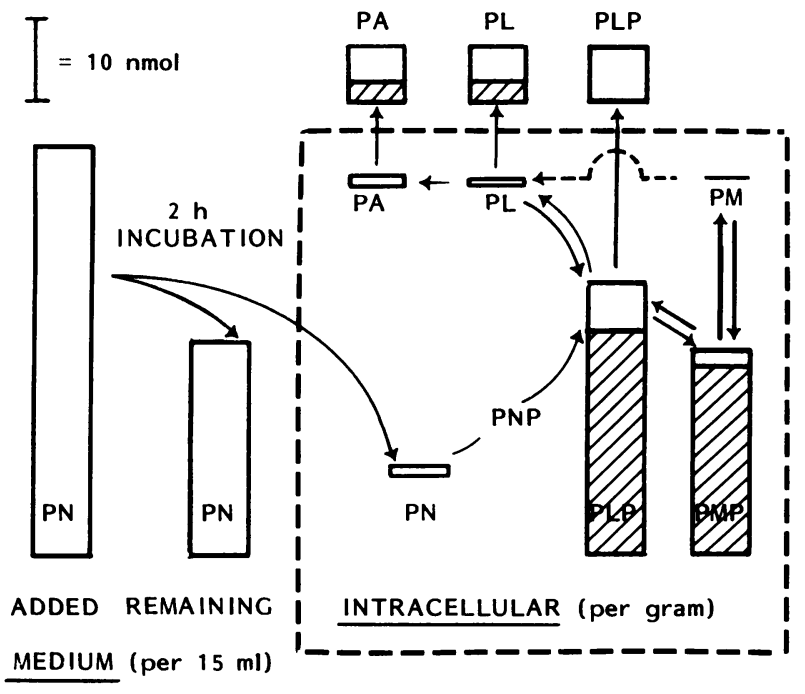

FIGURE 7 Schematic representation of the metabolic conversion of pyridoxine by isolated hepatocytes. The scheme depicts the amount of pyridoxine added at zero time and the content of pyridoxine and other $B_{6}$ compounds in the cells and the medium after $2 \mathrm{~h}$ incubation. The height of each bar represents the content of each $\mathrm{B}_{6}$ compound calibrated according to the scale shown. The clear areas represent $\left[{ }^{14} \mathrm{C}\right]-$ pyridoxine and its radiolabeled metabolic products, with a specific radioactivity of $12,053 \pm 6.35 \mathrm{cpm} / \mathrm{nmol}$. The shaded areas represent the endogenous nonradiolabeled pyridoxal-P and pyridoxamine- $P$ in isolated cells and their metabolic products released into the medium.

active organ in the metabolism of pyridoxine in vivo $(5-8)$. The results reported here with isolated hepatocytes also indicate that the liver cannot export pyridoxamine-P into the circulation (Fig. 4). This finding in vitro simulates the situation in vivo, wherein the plasma level of pyridoxamine-P failed to rise upon supplementation with oral pyridoxine.

Colombini and McCoy (6) have reported previously that, within $1 \mathrm{~min}$ after the intravenous injection of $\left[{ }^{14} \mathrm{C}\right]$ pyridoxine in a mouse, a large amount of radiolabeled pyridoxal appeared in the carcass. Similarly, Contractor and Shane (7) observed that the amount of radiolabeled pyridoxal exceeded the level of $\left[{ }^{14} \mathrm{C}\right]-$ pyridoxine in the brain and the fetus of pregnant rats shortly after the injection of $\left[{ }^{14} \mathrm{C}\right]$ pyridoxine. These observations suggested that there is either a high rate of direct conversion of pyridoxine to pyridoxal in these tissues or there is a rapid uptake of pyridoxal from the circulation into these tissues. If indeed the liver functions in vivo in a manner to convert rapidly ingested pyridoxine to plasma pyridoxal, this process favors the latter explanation for the aforementioned observations.

The pathways for the metabolic interconversion of the $B_{6}$ vitamers have been summarized by Snell and Haskell ([23], cf. Fig. 7). The stuḍies with isolated hepatocytes reported here provide further insights on the relationship of intracellular pool sizes and the metabolic flux of $B_{6}$ vitamers in the liver of $B_{6}$-sufficient animals. The major findings, summarized in Fig. 7, permit the following conclusions: ( $a$ ) Pyridoxal-P and pyridoxamine- $\mathrm{P}$ are the major endogenous $\mathrm{B}_{6} \mathrm{com}-$ pounds in liver cells, and their intracellular content is tightly regulated so that excess amounts of these coenzymes do not accumulate in the presence of nonphosphorylated $B_{6}$ precursors (24). (b) Newly synthesized pyridoxal-P and pyridoxamine-P do not exchange freely with endogenous intracellular pools of the coenzymes and, to a large extent, constitute a rapidly mobilizable pool destined for degradation and/or secretion into the circulation. (c) Pyridoxal-P, pyridoxal, and pyridoxic acid, but not pyridoxamine- $P$, are the principal $\mathrm{B}_{6}$ compounds released by the liver.

Although it has been suggested that pyridoxal kinase (25) and pyridoxine-P oxidase (26) may serve as control points in the regulation of pyridoxal-P metabolism, studies reported from our laboratory have emphasized the role of protein binding and the hydrolysis of unbound or loosely bound pyridoxal-P in governing the cellular level of this coenzyme (20). The results reported here suggest that hepatic pyridoxamine- $\mathrm{P}$, similar to pyridoxal-P, may also be regulated in this manner. Accordingly, newly synthesized pyridoxal-P and pyridoxamine-P, being unbound or loosely bound to $B_{6}$ enzymes, represent a rapidly mobilizable $B_{6}$ pool in liver. Pyridoxal-P, synthesized in excess, is either released into the medium or degraded to pyridoxal and pyridoxic acid. Whereas a transport mechanism does exist in liver for the secretion of pyridoxal-P, a similar mechanism is apparently absent for pyridoxamine-P. Thus, excess pyridoxamine- $\mathrm{P}$ is either transformed to pyridoxal-P or degraded to pyridoxamine and further oxidized to pyridoxal and pyridoxal acid. In addition to this functional compartmentalization, presumably due to coenzyme-protein interaction, structural compartmentation may also exist $(27,28)$.

\section{ACKNOWLEDGMENTS}

This work was supported by Veterans Administration Research Funds.

\section{REFERENCES}

1. Lyon, J. B. J., J. A. Bain, and H. L. Williams. 1962. The distribution of vitamin $B_{6}$ in the tissues of two inbred strains of mice fed complete and vitamin $B_{6}$-deficient rations. J. Biol. Chem. 237: 1989-1991.

2. Chabner, B., and D. Livingston. 1970. A simple enzymic assay for pyridoxal phosphate. Anal. Biochem. 34: 413423.

3. Chauhan, M. S., and K. Dakshinamurti. 1979. Fluorometric assay of pyridoxal and pyridoxal 5 '-phosphate. Anal. Biochem. 96: 426-432. 
4. Loo, Y. H., and W. M. Cort. 1972. Assay of pyridoxal and its derivatives. Methods Neurochem. 2: 169-204.

5. Johansson, S., S. Lindstedt, and H-G. Tiselius. 1968. Metabolism for $\left[{ }^{3} \mathrm{H}_{8}\right]$ pyridoxine in mice. Biochemistry. 7: $2327-2332$.

6. Colombini, C. E., and E. E. McCoy. 1970. Vitamin $B_{6}$ metabolism. The utilization of $\left[{ }^{14} \mathrm{C}\right]$ pyridoxine by the normal mouse. Biochemistry. 9: 53.3-5.38.

7. Contractor, S. F., and B. Shane. 1971. Metabolism of $\left[{ }^{14} \mathrm{C}\right]-$ pyridoxal in the pregnant rat. Biochim. Biophys. Acta. 230: $127-136$.

8. Johansson, S., S. Lindstedt, and H-G. Tiselius. 1974. Metabolic interconversions of different forms of vitamin $B_{6}$. J. Biol. Chem. 249: 6040-6046.

9. Lumeng, L., R. E. Brashear, and T-K. Li. 1974. Pyridoxal 5'phosphate in plasma: source, protein-binding and cellular transport. J. Lab. Clin. Med. 84: 334-343.

10. National Research Council, Committee on Animal Nutrition. 1972. Nutrient Requirements of Laboratory Animals. National Academy of Sciences-National Research Council, Washington, D. C. 2nd edition.

11. Edmondson, J. W., L. Lumeng, and T-K. Li. 1979. Comparative studies of alanine and $\alpha$-aminobutyric acid uptake by freshly isolated rat liver cells. J. Biol. Chem. 254: $1653-1658$

12. Edmondson, J. W., L. Lumeng, and T-K. Li. 1977. Direct measurement of active transport systems for alanine in freshly isolated rat liver cells. Biochem. Biophys. Res. Commun. 76: 751-757.

13. Lumeng, L. 1978. The role of acetaldehyde in mediating the deleterious effect of ethanol on pyridoxal 5 '-phosphate metabolism. J. Clin. Invest. 62: 286-293.

14. Lumeng, L. 1979. Hormonal control of ornithine decarboxylase in isolated liver cells and the effect of ethanol oxidation. Biochim. Biophys. Acta. 587: 556-566.

15. Contractor, S. F., and B. Shane. 1968. Estimation of vitamin $\mathrm{B}_{6}$ compounds in human blood and urine. Clin. Chim. Acta. 21: 71-77.

16. Reddy, S. K., M. S. Reynolds, and J. M. Price. 1958. The determination of 4-pyridoxic acid in human urine.J. Biol. Chem. 233: 691-696.

17. Bell, R. R., and B. E. Haskell. 1971. Metabolism of vitamin $B_{6}$ in the I-strain mouse. I. Absorption, excretion and conversion of vitamin to enzyme co-factor. Arch. Biochem. Biophys. 147: 588-601.

18. Anderson, B. B., C. E. Fulford-Jones, J. A. Child, M. E. J Beard, and C. J. T. Bateman. 1971. Conversion of vitamin $\mathrm{B}_{6}$ compounds to active forms in the red blood cell. $J$. Clin. Invest. 50: 1901-1909.

19. Mitchell, D., C. Wagner, W. J. Stone, G. R. Wilkinson, and S. Schenker. 1976. Abnormal regulation of plasma pyridoxal 5'-phosphate in patients with liver disease. Gastroenterology. 71: 1043-1049.

20. Lumeng, L., and T-K. Li. 1980. Mammalian vitamin $B_{6}$ metabolism: regulatory role of protein-binding and the hydrolysis of pyridoxal 5'-phosphate in storage and transport. In Vitamin $\mathrm{B}_{6}$ Metabolism and Role in Growth. G. P. Tryfiates, editor. Food and Nutrition Press Inc., Westport, Ct. $27-51$.

21. Sauberlich, H. E., J. E. Canham, E. M. Baker, N. Raica, Jr., and Y. F. Herman. 1972. Biochemical assessment of the nutritional status of vitamin $\mathrm{B}_{6}$ in the human. Am.J. Clin. Nutr. 25: 629-642.

22. Anderson, B. B., P. A. Newmark, M. Rawlins, and R. Green. 1974. Plasma binding of vitamin $B_{6}$ compounds. Nature (Lond.). 250: 502-5()4.

23. Snell, E. E., and B. E. Haskell. 1971. The metabolism of vitamin $\mathrm{B}_{6}$. Compr. Biochem. 21: 47-71.

24. Li, T-K., L. Lumeng, and R. L. Veitch. 1974. Regulation of pyridoxal 5'-phosphate metabolism in liver. Biochem. Biophys. Res. Commun. 61: 627-634.

25. Bukin, Y. V. 1976. Pyridoxal kinase activity and content of pyridoxal phosphate in mammalian tissues under normal and some experimental conditions. Biokhimiya. 41: $81-90$.

26. Merrill, A. H., K. Horiike, and D. B. McCormick. 1978. Evidence for the regulation of pyridoxal 5 '-phosphate formation in liver by pyridoxamine (pyridoxine) $55^{\prime}$-phosphate oxidase. Biochem. Biophys. Res. Commun. 83: 984990.

27. Lui, A., L. Lumeng, and T-K. Li. 1980. Stability of $B_{6}$ vitamers and location of pyridoxal-P hydrolase activity in isolated rat liver mitochondria. Fed. Proc. 39: 558.

28. Bosron, W. F., R. L. Veitch, L. Lumeng, and T-K. Li. 1978. Subcellular localization and identification of pyridoxal 5'-phosphate-binding proteins in rat liver. J. Biol. Chem. 253: 1488-1492. 